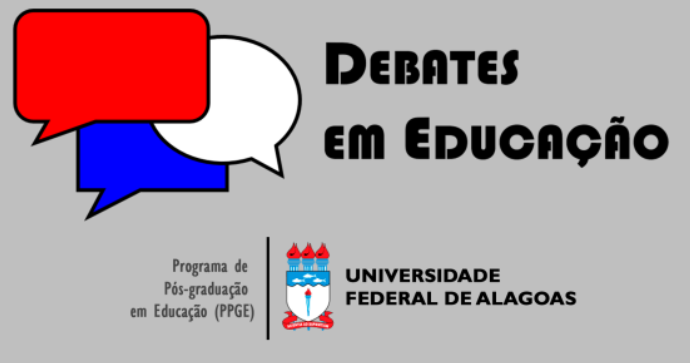

ISSN Eletrônico 2175-6600

Vol. 10 | No. 21 | Maio/Ago. | 2018

Francisco Marcos Pereira Soares Universidade Federal do Piauí (UFPI) marcosluhan@gmail.com

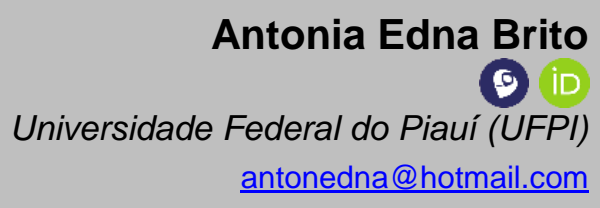

antonedna@hotmail.com

\section{IMPLICAÇÕES DA FORMAÇÃO DE PROFESSORES NA ANÁLISE E USO DO LIVRO DIDÁTICO DE ALFABETIZAÇÃO}

\section{RESUMO}

O estudo objetivou conhecer as implicações dos processos de formação de professores para a análise e utilização do livro didático em turmas do ciclo da alfabetização. Para fundamentar a investigação tomamos como referência, as contribuições teóricas de Imbernón (2002), Martins; Romanowski (2010), Pimenta (2011), Nóvoa (2002), Choppin (2004) Bitencourt (2004), Lajolo (1996), dentre outros. O aporte metodológico utilizado foi a pesquisa narrativa na perspectiva de Conelly e Clandinin (2011) tendo como dispositivo de produção de dados o memorial de formação. As revelações das interlocutoras possibilitam inferir que os usos e as funções atribuídos ao livro didático estão relacionados à prática docente e não há uma análise crítica em torno desse material.

Palavras-chave: Formação de professores. Livro didático. Prática Docente.

\section{IMPLICATIONS OF TEACHER TRAINING IN THE ANALYSIS AND USE OF THE DIDACT TEXTBOOK OF LITERACY}

\begin{abstract}
The study aimed to understand the implications of teacher education processes for the analysis and use of textbooks in classes of the literacy cycle. To base the research, we take as reference the theoretical contributions of Imbernón (2002), Martins; Romanowski (2010), Pimenta (2011), Nóvoa (2002), Choppin (2004), Bitencourt (2004), Lajolo (1996), among others. The methodological contribution used was the narrative research from the perspective of Conelly and Clandinin (2011) having as a data production device, the training memorial. The revelations of the interlocutors make it possible to infer that the uses and functions attributed to the textbook are related to the teaching practice and there is no critical analysis around this material.
\end{abstract}

Keywords: Teacher education. Textbook. Teaching Practice.

Submetido em: $12 / 10 / 2017$

Aceito em: 19/05/2018

DOI: $10.28998 / 2175-6600.2018 v 10 n 21 p 200-213$ 


\section{CONVERSAS PRIMEIRAS}

[...] o melhor dos livros não pode competir com o professor: ele, mais do que qualquer livro, sabe quais os aspectos do conhecimento falam mais de perto a seus alunos, que modalidades de exercício e tipos de atividade respondem mais fundo em sua classe e, ainda o caso é que não há livro que seja à prova de professor: o pior livro pode ficar bom na sala de um bom professor e o melhor livro desanda na sala de um mau professor.

Lajolo (1996, p. 06)

A epígrafe que abre a escrita do presente estudo esclarece o problema que norteou a realização da pesquisa, a saber: quais as implicações da formação de professores para a análise e utilização de livros didáticos em turmas do ciclo da alfabetização? O pensamento da autora nos convida a refletir acerca desse uso, ao tempo em que nos faz pensar sobre a problemática que envolve a formação de professores e as possíveis contribuições desse recurso didático como ferramenta de trabalho de professores alfabetizadores. Inicialmente, cabe-nos discutir a presença histórica desses materiais didáticos nas escolas brasileiras, reconhecendo a importância que o livro didático teve para a comunicação, produção e socialização do conhecimento escolar ao longo da história da nossa educação, fato que se tem intensificado, principalmente após 1995, quando foi criado o Plano Nacional do Livro Didático (PNLD), configurando-se como um marco fundamental para a inserção dessa ferramenta didática na cultura e no cotidiano escolar.

Pensar nestas questões suscita reflexões importantes para a construção de saberes e fazeres docentes, pois quando o professor elenca em sua formação uma bagagem intelectual suficiente para analisar os conteúdos trazidos pelos livros, sua prática pedagógica contemplará um processo de ensino e aprendizagem mais sólido, numa perspectiva mais reflexiva, consciente e com mais significados. Dessa maneira, compreender a formação do professor para a análise e a utilização do livro didático é relevante, uma vez que esse recurso ainda é a principal ferramenta de trabalho dos professores.

Nesse sentido, a formação inicial pode contribuir significativamente, quando desenvolve em seu currículo, atividade em que os futuros professores tenham oportunidade de conhecer as dificuldades que permeiam o uso desses materiais na escola e discutir a percepção que eles apresentam, de modo que adquiram saberes e conhecimentos que lhes possibilite fazer o uso mais consciente. Nesse sentido, é necessário discutir cada vez mais o papel da formação do professor e sua contribuição 
para a análise e utilização desse recurso didático, compreendendo-o como material da cultura da escola, que se relaciona com a prática e a formação docente.

Considerando o exposto, estabelecemos como objetivo geral: conhecer as implicações da formação inicial e continuada de professores alfabetizadores no uso de livros didáticos de alfabetização. A partir da delimitação desse objetivo, foram demarcadas as seguintes questões norteadoras: os processos de formação inicial e continuada de professores alfabetizadores contemplam atividades teóricas e práticas que favorecem a análise e utilização do livro didático? Professores alfabetizadores se sentem seguros e preparados para utilização do livro didático? Qual a importância que os professores alfabetizadores atribuem ao livro didático? Como utilizam esse material no processo de alfabetização e letramento das crianças?

Como aporte metodológico, desenvolvemos pesquisa narrativa, com abordagem qualitativa, e, como instrumentos de coleta de dados, utilizamos o memorial de formação. Participaram do estudo, três professoras alfabetizadoras, com formação inicial na área de Pedagogia, inseridas em processos de formação continuada proposta pelo Pacto Nacional pela Alfabetização na Idade Certa (PNAIC) e que estão em efetivo exercício da profissão em classes de alfabetização.

Nas reflexões teóricas sobre o tema, discutimos sobre a formação de professores e o uso do livro didático. Nesse sentido, postulamos que o modo como as professoras alfabetizadoras utilizam o livro didático está relacionado com os processos educativos vivenciados ao longo da formação e carreira docente. Em relação aos aspectos empíricos do estudo, discutimos teorias que subjazem ao uso desse material na alfabetização de crianças.

\section{FORMAÇÃO DE PROFESSORES E LIVRO DIDÁTICO}

Que proporcione um conhecimento válido e gere uma atitude interativa e dialética, que conduza a valorizar a necessidade de uma atualização permanente em função das mudanças que se produzem; a criar estratégias e métodos de intervenção, cooperação, análise, reflexão; a construir um estilo rigoroso e investigativo.

Imbernón ( 2002. p. 66)

Entendemos que as discussões sobre a formação de professores articuladas ao debate sobre análise de usos de livros de didáticos, sobretudo de alfabetização, pressupõem interações para além do campo disciplinar, especialmente, na inflexão de novas epistemologias, no sentido de problematizar pressupostos ultrapassados, 
contribuindo assim, para a formação de uma nova geração de professores alfabetizadores.

Consideramos que o livro didático, sobretudo na alfabetização, não se apresenta de natureza uniforme no decorrer da história de seu uso e de sua produção. Ao longo do século XX, por exemplo, puderam-se constatar mudanças de diferentes naturezas, relacionadas a esse impresso: heterogeneidade dos suportes; leitor ao qual se destina; função e utilização no processo de ensino e aprendizagem; natureza dos textos que contempla etc.

Para a presente investigação, consideramos importante descrever algumas considerações sobre formação de professores e usos que o professor tem feito do livro na organização da prática pedagógica, para que possamos entender o entendimento atual que os professores têm sobre ele.

De acordo com o glossário on-line do Centro de Alfabetização, Leitura e Escrita (CEALE), vinculado a Universidade Federal de Minas Gerais (UFMG):

O livro didático de alfabetização é um material didático impresso, organizado segundo determinada proposta pedagógica, uma progressão claramente definida e uma forma didática adequada às habilidades cognitivas próprias ao ensino e à aprendizagem dos processos de alfabetização e letramento, conhecimentos que se inserem na disciplina curricular de Língua Portuguesa.

Partindo desse conceito, é necessário que realizemos uma reflexão sobre os sujeitos que dão sentidos e significados a esses materiais dentro da escola, os professores. Alguns estudos, como o de Romanowski; Loch (2013) sobre o livro didático na prática pedagógica nos permitem refletir sobre a importância do professor nesse processo, cabendo-Ihe uma formação que favoreça práticas conscientes e reflexivas. Os autores (2007, pág.3):

[...] apontam que alguns professores o usam como instrumento de conhecimento e de métodos para o ensino constituindo-se em uma ferramenta de apoio e desenvolvimento da prática docente e consequentemente da aprendizagem do aluno, porém apontam também, que outros o usam não apenas como ferramenta, mas como direcionamento do ensino atribuindo-Ihe outras finalidades [...].

Os autores compreendem que o professor é quem executa as diferentes funções atribuídas ao livro didático, usando-o de forma convencional ou atribuindo-Ihes novas finalidades. Essas ideias passam pela compreensão de que esses usos perpassam pelas concepções de ensino que os professores têm inculcadas em suas práticas, a partir da formação que possuem e tiveram ao longo de sua história de profissionalização e construção de identidade. Dessa forma, o livro didático define o agir na prática docente, o currículo, as abordagens metodológicas e quadros conceituais (BATISTA, 2003). 
Consideramos que os diferentes usos desse material didático, tem intensa relação com a formação inicial e continuada de que o professor participa ao longo de sua profissionalização, norteando assim, suas decisões frente às práticas pedagógicas e ao uso de recursos didáticos. Durante a formação, seja ela inicial ou continuada, os professores são submetidos a determinadas situações de aprendizagem que podem favorecer a reflexão, o gosto pela pesquisa, a construção da autonomia e incitação à criatividade e à curiosidade. Por isso, o tipo de formação realizada pelo professor é fator fundamental para que determinadas práticas aconteçam de forma adequada ou não, na sala de aula.

Nessa perspectiva, quando se fala de usos de livros didáticos, o professor deve está preparado para compreender e analisar esses materiais e superar as dificuldades existentes, dependendo da instituição onde atua. Nesse campo, também se torna necessário debruçar-se sobre a necessidade de analisar esse livro didático.

Pensar nessa formação do professor é necessário, pois como afirma Romanatto (2004, p. 05) "há de se considerar que a importância do livro didático está condicionada ao tipo de prática que o docente faz dele". Lajolo (1996) também discute que o livro didático assumiu uma grande importância dentro da prática de ensino brasileiro nestes últimos anos, visto que a precária situação educacional faz com que acabe determinando conteúdos e condicionando estratégias de ensino, de forma decisiva. Considerando que o uso do livro didático depende das decisões docentes e do trabalho que ele se propõe a desenvolver, a finalidade desse recurso escolar está relacionada ao modo como é utilizado pelo professor.

Choppin (2004, p. 552) discute diversas funções que se pode atribuir ao livro didático em suas relações com os professores quando revela que:

[...] os livros escolares assumem, conjuntamente ou não, múltiplas funções: o estudo histórico mostra que os livros didáticos exercem quatro funções essenciais, que podem variar consideravelmente segundo o ambiente sociocultural, a época, as disciplinas, os níveis de ensino, os métodos e as formas de utilização. A função referencial, instrumental, ideológica e cultural e documental.

Analisando cada uma dessas funções, podemos refletir que a função referencial diz respeito ao currículo orientador dos conteúdos, por isso, também pode ser chamada de função curricular, por trazer referenciais de saberes que uma comunidade considera necessários para que sejam explicitados e ensinados para outras pessoas.

Quando a autora se refere à função instrumental do livro didático, explicita o fato de ele constituir-se em um referencial de métodos ou estratégias de aprendizagem por meio de sequências didáticas de aprendizagem, com atividades relacionadas aos mais 
variados conteúdos que se apresentam com finalidades de desenvolver memorizações, resolução de situações-problema, competências disciplinares, entre outros.

Tendo a função também, na transmissão de ideologias e de cultura vigente, compreendemos o livro didático como uma ferramenta privilegiada na construção da identidade dos educandos, na transmissão das diferentes linguagens, no ensino da língua materna, na transmissão e construção de valores e da cultura.

Com função também documental, os materiais didáticos apresentam-se como um conjunto de documentos, textuais ou ícones dentro da cultura escolar, cujo contato, interação, observação ou mesmo a confrontação, pode desenvolver o pensamento crítico dos educandos, ou seja, o livro didático ultrapassa sua própria função referencial (CHOPPIN, 2004).

Pensando sobre essas funções, é possível dizer, que a quarta função mencionada, ainda não foi universalizada, cabendo um nível de formação mais aprofundado dos professores para que possam compreender melhor esse recurso didático, aprendam a realizar uma análise crítica do mesmo e utilizem-no da forma mais significativa e consciente possível.

\section{PERCURSOS METODOLÓGICOS}

Estabelecemos como método de pesquisa a narrativa, por compreendermos que possibilita o conhecimento da realidade pesquisada em diferentes nuances. Clandinin e Connely (2011) definem pesquisa narrativa como "uma forma de entender a experiência" em um processo de colaboração entre pesquisador e pesquisado.

Entre tantas técnicas de produção de dados que estão à disposição dos estudiosos, destacamos as vozes dos memoriais ou narrativas formativas, como uma metodologia propícia para investigar os percursos pessoais e profissionais. O memorial constitui um tipo textual que se distingue de outros textos por apresentar as "memórias" de quem escreve. Partindo-se da concepção dialógica entre o 'eu' e o 'outro', proposta pelo filósofo Mikhail Bakhtin (2011), é possível considerar o trabalho com o memorial como um estar no outro e ser o outro. Para esse filósofo (BAKHTIN, 2011, p. 341), o sujeito não se detém em um único território interior; ele sempre vai demarcar sua fronteira, olhando para dentro de si com "o outro nos olhos ou com os olhos do outro". Com base nessa perspectiva, é que consideramos que a narrativa dos memoriais possibilita o envolvimento de quem pesquisa e dos sujeitos pesquisados em um processo 
de investigação que se constrói com o outro. A perspectiva dialógica permeia as relações entre aqueles que narram e os acontecimentos de sua trajetória.

A investigação foi realizada com participação de três alfabetizadoras que se encontram em efetivo exercício da profissão docente, em classes de alfabetização. Para a definição das interlocutoras do estudo, observamos os seguintes critérios: a) ser formada em Pedagogia e trabalhar como alfabetizadora em escola da rede pública; b) participar de formação continuada de professores e c) aderir à pesquisa de forma consciente, disponibilizando-se à narrativa escrita de um memorial.

As interlocutoras da pesquisa ao narrarem sobre seus perfis profissionais afirmam:

[...] Sou Pedagoga pela Universidade Estadual do Piauí, minha formação aconteceu de forma aligeirada devido ser curso de férias, trabalho há dez anos no município. Participo de formações continuadas que o município oferece. Considero que minha formação inicial me deixou muitas lacunas de aprendizagem e hoje corro atrás para suprir as minhas insuficiências frente a metodologias de ensino e ao uso dos recursos didáticos. (Professora Ju)

[...] Trabalho na zona rural [...] como professora alfabetizadora. Minha formação é Pedagogia. Minhas primeiras experiências como professora foram desafiadoras e alguns destes desafios ainda continuam na minha profissão. Reconheço a necessidade de participar de cursos, oficinas, palestras que o município oferece. [...] Trabalho como alfabetizadora há 15 anos. (Professora Gil)

Trabalho como alfabetizadora no município [...], sou graduada em Pedagogia [...], participo de todas as formações que o município oferece, entre elas o PNAIC. Minha turma é do $2^{\circ}$ ano, e as crianças ainda não estão todas alfabetizadas. Logo, preciso me capacitar cada vez mais para melhorar minhas práticas. (Professora Lia)

De acordo com os dados da pesquisa presentes nos memoriais escritos pelas interlocutoras, todas possuem graduação em Pedagogia, um dos critérios da investigação; consideram importante a capacitação em serviço e por isso, participam de formação continuada ofertada pelo município em que trabalham (cursos, palestras, oficinas, formação de programas federais como o PNAIC. Trabalham no ciclo de alfabetização e discutem a complexidade do trabalho docente, sobretudo na alfabetização, o que sugere qualificação profissional constante.

\section{ANÁLISE E EVIDÊNCIAS DA PESQUISA: REVELAÇÕES DOS MEMORIAIS}

A análise do uso de livros didáticos usados na alfabetização de crianças no contexto escolar, articulada à discussão sobre formação de professores tem suscitado muitas discussões. Indaga-se sobre a formação inicial e continuada de professores e os 
momentos destinados a estudos sobre o livro didático. Questiona-se a preparação do professor, a fim de compreender o livro didático no contexto dessa formação, bem como, as percepções do professor sobre a necessidade de analisar os livros didáticos de alfabetização.

Tais discussões apontam que os professores apresentam-se, no geral, despreparados para analisar o livro didático e os utilizam, muitas vezes, em sua dimensão referencial ou curricular, demonstrando com isso, determinadas lacunas em seus cursos de formação, tanto inicial, quanto continuada, que não se mostram elencadas de dispositivos que possibilitem ao professor desenvolver essa habilidade de dimensão formativa.

Para abordar essa temática, nos respaldamos nos referidos questionamentos, bem como nos demais dados da pesquisa, a fim de responder às indagações norteadoras do estudo, as quais foram organizados em três unidades temáticas, conforme Quadro 1:

\section{Quadro1: Temáticas de análise}

\begin{tabular}{|l|}
\hline \multicolumn{1}{|c|}{ Temáticas } \\
\hline $\begin{array}{l}\text { 1. A formação inicial e continuada de professores e os momentos destinados a estudos sobre o } \\
\text { livro didático. }\end{array}$ \\
\hline $\begin{array}{l}\text { 2. A preparação do professor para compreender o livro didático a partir da formação que } \\
\text { possui }\end{array}$ \\
\hline $\begin{array}{l}\text { 3. As percepções do professor sobre a necessidade de analisar os livros didáticos de } \\
\text { alfabetização. }\end{array}$
\end{tabular}

Fonte: Dados dos memoriais (2017)

\subsection{A formação inicial e continuada de professores e estudos sobre o livro didático}

Considerando que o livro didático está inserido na prática docente - e não somente o livro de alfabetização e letramento - e que ele é suporte de outros aspectos passíveis de análise, além de metodologias, o espaço destinado à análise crítica dos livros didáticos nos cursos de pedagogia é ineficiente. No contexto deste estudo, percebemos que a formação inicial vivida pelas interlocutoras revela muito dos seus modos de lidar com o livro didático. Elas se referem ao curso de Pedagogia realçando que:

Meu curso de Pedagogia foi maravilhoso. Gosto muito de ser Pedagoga. Mas, analisando hoje as demandas da sala de aula, a quantidade de recursos a serem utilizados nas escolas, especialmente a responsabilidade de usar o livro didático de forma cuidadosa, percebo deficiências e lacunas na minha formação. Uso o livro diariamente retirando dele as atividades necessárias para minha rotina. Se me perguntarem se eu reflito sobre o que determinadas coisas querem dizer por trás daquilo tudo eu sou sincera em afirmar que não sei dizer muita coisa. O curso de Pedagogia traz muita teoria e foi desta forma que aprendemos a analisar. $\mathrm{Na}$ 
formação continuada, participamos de algumas atividades que permitem refletir sobre esse assunto. Por exemplo, o PNAIC que é a formação ofertada na secretaria de educação do município aborda esse tema. Eu particularmente gosto muito, mas considero minha formação ainda muito tímida nesse sentido. (Professora Ju)

Os estudos sobre livros didáticos na minha graduação, se não falha a memória, aconteceram em duas ou três disciplinas de forma muito teórica. Abordagens que hoje, na realidade da sala de aula, me ajudam pouco a pensar em todas as dimensões, funções que o livro tem. Acredito que temos que aprofundar mais os conhecimentos acerca do livro numa dimensão documental que ao interagir com ele se possa desenvolver a criticidade, saber confrontar-se com as ideias ali presentes. Sei dessa necessidade, mas não sei muito como trabalhar isso comigo mesmo e com meus alunos, principalmente na fase de alfabetização. Estou buscando aprofundar isso nas formações de que tenho participado. [...] É necessário. (Professora Gil)

Os momentos de estudos de livros didáticos na minha formação foram muito poucos. Minha graduação em Pedagogia me ofertou muito pouco esses saberes. $\mathrm{Na}$ época, parece que queríamos muito cumprir com as "cadeiras" e não senti tanta falta. Hoje, com certeza, vejo uma necessidade de que todos os professores compreendam, analise e usem os livros didáticos conscientemente. Eles dizem muito sobre a formação que estamos dando a nossas crianças. Faço algumas análises do livro, a partir dos desafios que me são imposto no cotidiano da sala de aula. (Professora Lia)

A pouca formação das interlocutoras sobre as questões que envolvem o livro didático, somada à complexidade das práticas docentes, faz com que elas percebam a necessidade de participar de formações continuadas. No diálogo com as alfabetizadoras, ficou claro que o que apreenderam no curso de Pedagogia diz respeito apenas a aspectos teóricos, e, em consequência, foram orientados a analisar o livro didático de forma teórica.

Esses comentários apontam que o professor se aproxima da formação continuada, a partir das situações vividas na prática docente, o que vai de encontro ao pensamento de Nóvoa (2002), quando aponta que a formação continuada do professor deve estar articulada com o desempenho profissional, tomando a escola como lugar de referência. Outros professores sinalizam a prática docente como momento significativo de aprendizado sobre o livro didático.

As interlocutoras apontam ainda, que a teoria recebida no curso não dá suporte para a prática neste sentido. Romanowski; Martins (2010) contribuem com esta análise, quando destacam que a concepção de relação teoria e prática que orienta as disciplinas de didática nos cursos de Pedagogia tende a priorizar a aplicação dos conhecimentos teóricos na prática. Em outros termos, a concepção de teoria como guia da ação reafirma a dicotomização desses dois polos do conhecimento. 


\subsection{A preparação do professor para compreender o livro didático a partir da sua} formação

O professor está preparado para compreender o livro didático a partir da formação inicial que possui? Compreendemos que os livros didáticos precisam ser analisados e usados, tendo por base as funções que Ihe são atribuídas: função referencial, instrumental, ideológica e cultural e também documental, de acordo com Choppin (2004), de forma que essa interação seja consciente e significativa. Jamais o livro pode se tornar o "senhor" da razão dentro da sala de aula, sob o erro de engessar rituais escolares nos quais pouco se aprende ou se aprende de maneira mecanizada, tanto por parte de quem ensina, quanto por parte de que aprende. Sobre essa questão as interlocutoras apontam que:

[...] me sinto preparada para dar aulas, mas para realizar análise de livros em todas as suas dimensões não. Percebemos nossa dificuldade durante o próprio processo de escolha quando a secretaria de educação nos convoca para ver os exemplares trazidos pelas editoras enviados pelo PNLD. Claro que durante nossas práticas na sala de aula vamos apresentando certas dificuldades e vamos tirando nossas conclusões sobre os livros que são bons ou não para alfabetizar as crianças, para trabalhar com as crianças. (Professora Ju)

Vejo que as práticas de sala de aula têm me preparado muito para diversos desafios que me são postos na sala de aula. O livro didático chega a nossas mãos de uma forma muito "violenta, brusca" e não temos muito o que dizer desses livros. Nossa própria formação deveria dar conta disso e não deu. Saber analisar os livros e a utilizá-los se torna dois grandes desafios. Não quero dizer que não tenho competência para dar aulas, mas acho que existem outras formas de uso e talvez até reformulações daquilo que vem posto só para nós executarmos. (Professora Gil)

Os livros didáticos de alfabetização, sobretudo, parecem algo muito fácil, parecem todos iguais a priori. Mas é importante que saibamos analisar cada texto, cada imagem, formato, atividades e sequências propostas. Não sei muito bem, mas faço isso às vezes, porque me preocupo com a formação das crianças e o tipo de aula que estou oferecendo para cada uma delas. No geral, preciso aprender muito sobre esses livros. (Professora Lia)

As interlocutoras demonstram saber a importância que as práticas de ensino possuem nessa interação com o livro didático e o quanto esse manuseio leva-as a compreender esses materiais tão importantes na cultura escolar. Nos seus diálogos, as alfabetizadoras esclarecem a necessidade dessa compreensão sobre o assunto, já que a formação inicial não deu conta de instrumentalizá-las para a análise de uso desse material, ressaltando, porém, a importância que as práticas cotidianas possuem para reflexão sobre esses materiais em sala de aula. Tais discussões permitem inferir que prática docente foi o primeiro espaço que tiveram contato com o livro didático e por meio dele, foram aprendendo na e pela experiência. 
Pimenta (1999) chama a atenção, destacando que a mera repetição diária de situações não constitui conhecimento. Logo, se a formação inicial ou continuada não deu embasamento sobre conteúdos relativos ao livro didático e o professor não tiver acesso ou mesmo não buscar esses saberes em outros processos formativos, a análise e o uso desses recursos didáticos se tornarão mecânicos e roteirizados e os alfabetizadores e alfabetizandos serão leitores de sequências prontas e acabadas.

\subsection{As percepções do professor sobre a necessidade de analisar os livros didáticos de alfabetização}

O espaço escolar, sobretudo as salas de aula, é o ambiente onde, para o professor, emergem os significados que dão sentido aos saberes adquiridos no curso de Pedagogia ou mesmo a falta desses saberes. Daí, investigarmos se os professores consideram importante saber analisar o livro didático. Em diversos momentos de suas narrativas, as interlocutoras deixam claro suas angústias e experiências tímidas no trato com as questões que envolvem a análise e, muitas vezes, a utilização desses materiais em suas práticas docentes. Vejamos o que elas destacam:

A minha concepção é que necessitamos sim avaliar e reavaliar os materiais didáticos que usamos em nossas aulas. Entre eles, os livros didáticos são o principal, pois eles trazem não só os conteúdos curriculares; trazem também diversas ideologias que precisam passar por uma peneira reflexiva. Ou seja, considero importante analisar tanto aquilo que ele traz como também considero importante refletirmos a maneira como estamos usando esses livros, principalmente com a alfabetização. (Professora Ju)

Tenho dificuldades em realizar essa avaliação dos livros. Mas considero importante que todos os professores aprendam a fazer essa análise, a refletir sobre as maneiras como usam esses livros, notadamente quando se fala de pedagogos e de práticas de alfabetização. É preciso se questionar: que material estou usando para alfabetizar e de que forma estou usando esses materiais e se considero estes suficientes para dar conta da formação das crianças. Então, é uma discussão complexa e necessária. (Professora Gil)

Não desconsidero a teoria apresentada para nós professores enquanto estudávamos no curso de pedagogia. Ao tempo em que considero um assunto muito sério e deveria ser dada maior importância a isso na hora de formar professores. Essa questão e algo que faz parte da cultura da escola. É algo propriamente da escola, da formação de pessoas. Então é importante que aconteça. A análise e uso dos livros didáticos precisam sim ser repensados. (Professora Lia)

Os diálogos evidenciam uma preocupação significativa das interlocutoras em torno da questão analisada e colocam a análise do livro didático e sua utilização no centro das discussões. Compreendem as diversas dimensões e atribuições que esses recursos possuem, bem como, a necessidade de que os professores estejam preparados para 
receber esses materiais e fazerem bom uso deles. Atividade que exige formação, reflexão, criatividade e compromisso com a educação das crianças.

Também, é possível identificar o valor atribuído às práticas docentes para uma reflexão maior sobre o livro didático, sobretudo de alfabetização, fase em que a criança formaliza suas ideias e práticas sobre leitura e escrita. Sobre essa questão, Pimenta (1999) afirma que os saberes só se constroem no confronto e no diálogo com a prática, quando há condições de análise e reflexão à luz dessas práticas. Ao entrar em sala de aula e se deparar com a necessidade do uso do livro didático, inconscientemente, o professor articula seus conhecimentos entre teoria e prática, ou seja, faz um movimento dos sentidos da prática com os significados da teoria.

As revelações das alfabetizadoras também esclarecem uma preocupação com seus educandos, quando veem a necessidade de analisar os materiais que são apresentados às crianças, entre eles os livros didáticos já que são, na maioria das vezes, o único material de leitura que têm acesso. Bitencourt (1998) contribui com esta discussão, quando esclarece que o livro didático é, de fato, o principal veiculador de conhecimentos sistematizados e o produto cultural de maior divulgação entre os brasileiros que têm acesso à educação escolar.

Lajolo (1996) ressalta que a análise crítica do livro didático reforçará a posição do professor em todas as práticas que constituem sua tarefa docente, e, portanto, no dia a dia ele reescreve o livro didático reafirmando-se, neste gesto, como sujeito de sua prática pedagógica um quase coautor do livro didático.

\section{CONSIDERAÇÕES FINAIS}

A pesquisa realizada com alfabetizadoras, pedagogas da rede pública de ensino, com o objetivo de investigar as implicações da formação inicial e continuada de professores alfabetizadores no uso dos livros didáticos de alfabetização nos remete a muitas reflexões. As revelações da pesquisa possibilitaram inferir que, as funções atribuídas ao livro didático são relacionadas à prática docente sem o devido estudo crítico, durante a formação inicial de professores, pois as professoras indicam que o curso de Pedagogia não as instrumentalizou para a prática. Desse modo, o curso não se constitui momento significativo para o estudo do livro didático, mesmo que conteúdos relativos às metodologias do livro didático tenham sido discutidos ao longo do curso.

Também foi possível perceber que pouco se estuda o livro didático, quer seja numa dimensão técnica, que seja numa dimensão crítica. Verificou-se ainda, que as professoras 
possuem pouca formação para realizarem estudos mais aprofundados sobre o livro. Elas preocupam-se com essa questão, devido à qualidade da aprendizagem das crianças, mas pouco se mobilizam para tal estudo, mesmo que apresentem dificuldades no uso deste material pedagógico. Afirmam que tentam suprir essa carência de formação, a partir de suas próprias práticas ou em momentos de formação continuada ofertadas pelo município em que trabalham.

É importante destacar que essa é uma discussão complexa e não pode ser encerrada apenas com a presente pesquisa. Entende-se que não foram analisados documentos que formalizam o funcionamento dos cursos, nas instituições em que as professoras realizaram seus cursos de Pedagogia. Pretende-se conseguir uma melhor concepção acerca da formação de professores relacionada à discussão da análise e uso do livro didático, compreendendo-se a importância da continuidade dessa discussão, na tentativa de aprofundar os conhecimentos sobre a temática.

\section{REFERÊNCIAS}

BAKHTIN, M. Estética da criação verbal. São Paulo: Martins Fontes, 2011.

BATISTA, A. Augusto G. Avaliação dos livros didáticos: para entender o Programa nacional do livro didático (PNLD). In: ROJO, Roxane; BATISTA, Antonio Augusto Gomes. Livro didático de língua Portuguesa, letramento e cultura escrita. Campinas: Mercado das Letras, 2003. p. 25-67.

BITTENCOURT, Circe M. F. Em foco: história, produção e memória do livro didático. Revista Educação e Pesquisa. v. 30, № 3. São Paulo: EDUSP. Set/dez. 2004.

BRASIL. Resolução CNE/CP de 15 de maio de 2006. Institui Diretrizes Curriculares nacionais para o curso de graduação em Pedagogia. Diário Oficial da União. Brasília, 10 maio 2006. Seção 1, p. 11. Disponível em: < http://portal.mec.gov.br/cne/arquivos >. Acesso em: 01 jun. 2017.

CHOPPIN, A. A história dos livros e das edições didáticas: sobre o estado da arte. Educação e Pesquisa. São Paulo: v.30, n.3, p.549-566, set / dez.2004.

CLANDININ, D. Jean; CONNELLY, F. Michael. Pesquisa narrativa: experiência e história em pesquisa qualitativa. Tradução: Grupo de Pesquisa Narrativa e Educação de Professores ILEEI/UFU. Uberlândia: EDUFU, 2011.

IMBERNÓN, F. Formação docente e profissional: formar-se para a mudança e a incerteza. 3. ed. São Paulo: Cortez, 2002. 
LAJOLO, M. Livro didático: um (quase) manual de usuário. Em aberto. Brasília, v. 26, n. 69, p.3-7, jan/março, 1996.

LOCH, V. de F. V.; ROMANOWISKI, J. P. O livro didático e a formação de professores. In: Anais XI Congresso Nacional de Educação. Curitiba, 2013.

MARTINS, P. L. O.; ROMANOWSKI, J. P. A didática na Formação Pedagógica de Professores. Educação (PUCRS. Impresso) v. 33, p. 205-212, 2010.

NÓVOA, A. Formação de professores e trabalho pedagógico. Lisboa: Educa, 2002.

PIMENTA, S G.; GHEDIN, E. (Org.) Professor reflexivo no Brasil: gênese e crítica de um conceito. São Paulo: Cortez, 1999.

ROMANATTO, M. C. A noção de número natural em livros didáticos de Matemática: comparação entre textos tradicionais e modernos. 152f. Dissertação (Mestrado em Metodologia de Ensino) - Centro de Educação e Ciências Humanas, Universidade Federal de São Paulo, São Carlos, 2004.

ROMANOWSKI, J. P.; MARTINS, P. L. A didática na formação pedagógica de professores. Educação. Porto Alegre: PUCRS, v. 33, n. 3, p. 205-212, set/dez. 2010.

SILVA, C. S. B. Curso de Pedagogia do Brasil: história e identidade. 3. ed. Campinas: Autores Associados, 1999. 